\title{
Apparent reduction of endogenous creatinine clearance by salicylate treatment
}

\author{
H C BURRY, P A DIEPPE
}

British Medical fournal, 1976, 2, 16-17

\section{Summary}

A prospective study of nine patients with rheumatoid arthritis and 11 healthy volunteers who started salicylate treatment showed that in 18 of the 20 subjects creatinine clearance values fell, the average being $25^{\circ}$. Serum creatinine concentration was increased by an average of $38 \%$, although blood urea levels were unchanged. Since ${ }^{51} \mathrm{Cr}$-edetic acid clearance tests performed at the same time in 12 of the subjects were not affected, the fall in creatinine clearance was probably not due to impaired glomerular function, and salicylate ingestion may therefore invalidate the creatinine clearance test as an index of glomerular filtration rate. It is clearly important to inquire into the patient's analgesic consumption when using the creatinine clearance test to assess glomerular function.

\section{Introduction}

The endogenous creatinine clearance test was introduced into medicine by Popper and Mandel $^{1}$ in 1937 and remains a con-

Guy's Arthritis Research Unit, Guy's Hospital Medical School, London SE1 9RT

H C BURRY, FRCP, FRACP, physician in charge, department of rheumatology

P A DIEPPE, BSC, MRCP, registrar (now research registrar, department of rheumatology and experimental pathology, St Bartholomew's Hospital, London $\mathrm{EC1} 7 \mathrm{AB}$ ) venient method of estimating the glomerular filtration rate. Although creatinine clearance in man has usually been found to be higher than inulin clearance, and is particularly likely to be falsely high in severe renal disease ${ }^{2}$ and unreliable in patients with the nephrotic syndrome, ${ }^{3}$ there has hitherto been little information about the possible effects of drug treatment on creatinine clearance. Beeley and Kendall ${ }^{4}$ showed that a single oral dose of salicylate reduced clearance of ${ }^{125} \mathrm{I}$-diatrizoate but could not determine whether this change was due to a fall in clearance of the test substance or a change in the glomerular filtration rate. Subsequently Robert $e t$ al ${ }^{5}$ recorded a transient fall in both inulin and creatinine clearance when an intravenous infusion of salicylic acid was started. We studied the effect of 10 days' oral salicylate treatment on ${ }^{51} \mathrm{Cr}$-edetic acid clearance, blood urea and serum creatinine levels, and creatinine clearance.

\section{Method}

Nine patients with rheumatoid arthritis who had never received salicylate treatment and 11 healthy volunteers were studied. None of the 20 subjects had any history of renal disease. Blood urea and serum creatinine concentrations and creatinine clearance were measured before the subjects started a regimen of aloxiprin of two tablets four times daily (equivalent to about $4 \mathrm{~g}$ salicylate daily) and again after three and 10 days of treatment. In 12 cases ${ }^{51} \mathrm{Cr}$-edetic acid clearance was measured on the same days so that any variation in recorded values could be compared with changes in creatinine clearance. Creatinine was assayed using the Technicon AutoAnalyzer, and ${ }^{51} \mathrm{Cr}$-edetic acid clearance was estimated according to the method described by Stacy and Thorburn. ${ }^{6}{ }^{51} \mathrm{Cr}$-edetic acid clearance was chosen as a check of the validity of the creatinine clearance results because of its convenience and close correlation with inulin clearance. $^{78}$

Results in normal subjects and patients with rheumatoid arthritis

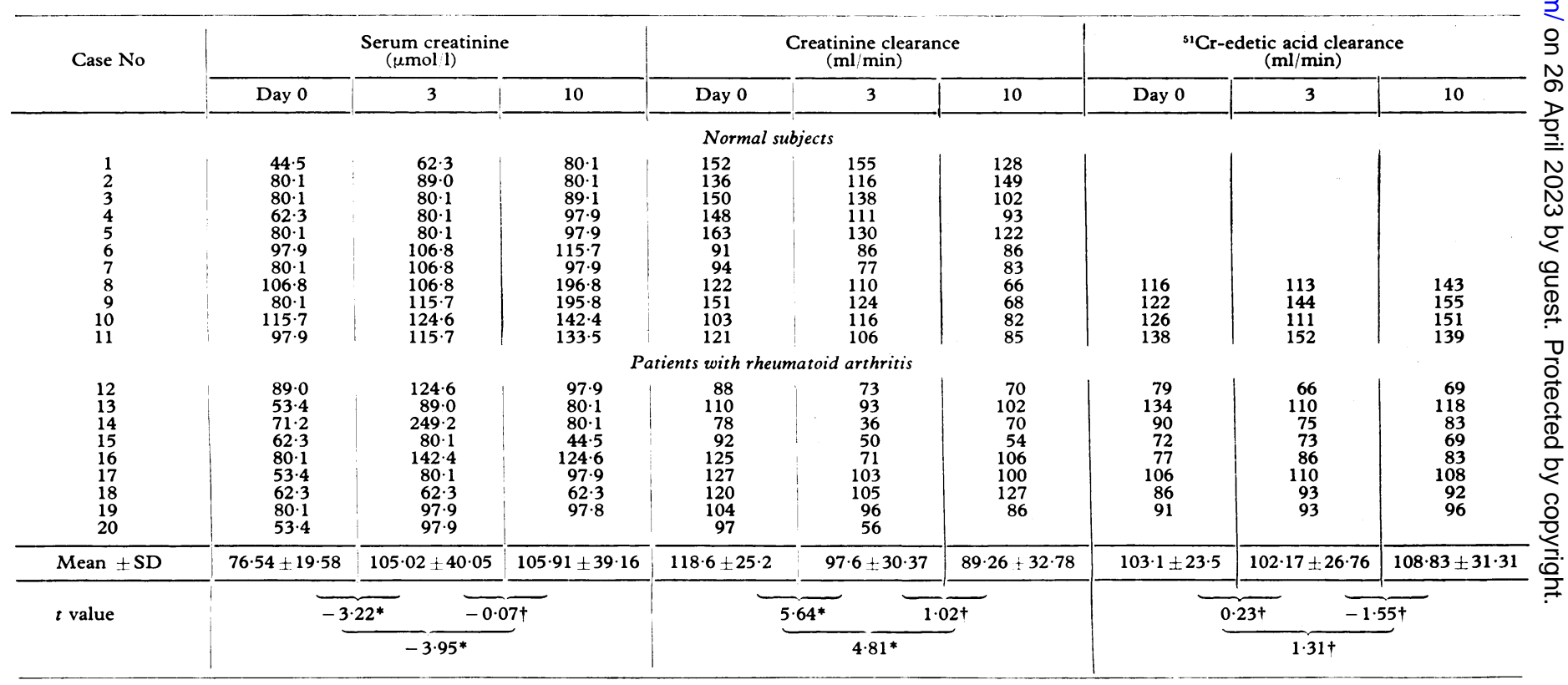

*P<0.01. †Not significant.

Conversion: SI to traditional units-Serum creatinine: $1 \mu \mathrm{mol} / 1 \approx 0.0113 \mathrm{mg} / 100 \mathrm{ml}$. 


\section{Results}

The blood urea values did not alter appreciably and are not shown. The results of the other investigations are shown in the table. After 10 days, in all but one patient in each group, the creatinine clearance fell, the average decrease being about $25^{\prime \prime} .(\mathbf{P}<0.01)$. At the same time the serum creatinine level rose by an average of about $38^{\prime \prime}$. $(\mathrm{P}<0.01)$. Most of the change in creatinine clearance occurred in the first three days; the further small decrease in creatinine clearance between day three and day 10 was not statistically significant. These results contrasted considerably with the ${ }^{i 1} \mathrm{Cr}$-edetic acid clearance figures, which showed no significant change.

\section{Discussion}

Our results indicate that salicylate treatment was associated with a sustained increase in plasma creatinine levels and a fall in creatinine clearance. Since chromium edetate clearance remained unaffected it is reasonable to assume that these changes did not result from a disturbance of glomerular function, unless salicylate induces a specific interference with filtration of creatinine in the glomerulus. More likely explanations include disturbance of creatinine binding to serum protein or competitive inhibition of tubular secretion of creatinine. The further possibility of abnormal production of creatinine is unlikely as analysis of the daily output of creatinine showed no increase in total excretion. To ensure that the presence of salicylate in plasma had not interfered with the assay of creatinine, salicylate in a concentration of $1.5 \mathrm{mmol} / 1(20 \mathrm{mg} / 100 \mathrm{ml})$ plasma was added to eight specimens of serum. Assays of creatinine with and without salicylate showed no difference in the results.
Clearly the creatinine clearance test is not suitable for assessing renal function in patients suffering from rheumatoid arthritis since many of these will be receiving salicylate, and the results of the investigations carried out by Sørensen, ${ }^{9}$ Bulger et al, " Burry, ${ }^{11}$ Jeremy et al, ${ }^{12}$ and the New Zealand Rheumatism Assoziation study ${ }^{13}$ need to be reassessed in this context. Further studies are indicated to determine whether other drugs have an effect on creatinine clearance similar to that of salicylates and to determine the mode of action of salicylates.

When the creatinine clearance test is used to detect renal disease or monitor progress of renal disease a careful history of the patient's drug-taking habits must be obtained before the results can be assessed.

\section{References}

1 Popper, H, and Mandel, E, Ergebnisse der Inneren Medizin und Kinderheilkunde, 1937, 53, 685 .

2 Miller, B F, et al, fournal of Clinical Investigation, 1952, 31, 309

"3erlyn, G M, et al, Lancet, 1964, 2, 874.

' Beeley, L, and Kendall, M J, British Medical Fournal, 1971, 1, 707.

'Robert, M, et al, British Medical fournal, 1972, 2, 466.

"Stacey, B D, and Thorburn, G D, Science, 1966, 152, 1076.

- Garnett, E S, Parsons, V, and Veall, N, Lancet, 1967, 1, 818

" Favre, H R, and Wing, A J, British Medical fournal, 1968, 1, 84

${ }^{9}$ Sørensen, A W S, Acta Rheumatologica Scandinavica, 1960, 6, 115.

11) Bulger, R J, Healey, L A, and Polinsky, P, Annals of the Rheumatic Diseases, 1968, 27, 339.

' Burry, H C, Annals of the Rheumatic Diseases, 1972, 31, 65.

1: Jeremy, R, et al, Australian Rheumatism Association's Annual Meeting Proceedings, 1972, Abstract 15, p 12.

${ }^{13}$ New Zealand Rheumatism Association, British Medical fournal, 1974, 1, 593.

\title{
Doppler ultrasound method for detecting human fetal breathing in utero
}

\author{
E S BOYCE, G S DAWES, J D GOUGH, E R POORE
}

British Medical fournul, 1976, 2, 17-18

\section{Summary}

An audible Doppler ultrasound method for detecting human fetal breathing movements in utero has been developed. The frequencies synchronous with fetal breathing movements probably originate from the lung rather than the chest wall. This method is much cheaper and simpler than the ultrasound A-scan method and is suitable for screening large numbers of people.

\section{Introduction}

Over the past five years fetal breathing movements in utero have been investigated in sheep and in $\operatorname{man}^{1 *}$ using an ultrasound

\footnotetext{
Nuffield Institute for Medical Research, University of Oxford, Oxford OX3 9DS

E S BOYCE, MB, MRCOG, research officer

G S DAWES, DM, FRS, director

J D GOLGH, MB, MRCOG, research officer

E R POORE, BSC, research assistant
}

A-scan method, and there is evidence that the continued presence of normal fetal breathing is an index of health. ${ }^{3}$ The A-scan method, however, requires expensive and complex machines that need considerable practise to use, and it is unsuitable for screening large numbers of patients. We therefore searched for a simple method of detecting fetal breathing movements.

\section{Technique}

The maximum velocity of human fetal chest wall movements in utero is only $1-3 \mathrm{~cm} / \mathrm{s}$ as measured by A-scan ultrasound; this was confirmed using a pulsed Doppler system giving a shift frequency $<70 \mathrm{~Hz}$ with a transducer pulsed at $2 \mathrm{MHz} .{ }^{4}$ This shift frequency is rejected by the filtering in most continuous Doppler systems available clinically.

Nevertheless, audible signals of a character consistent with fetal breathing (fig 1) were obtained using a Sonicaid D205 instrument in more than 70 pregnant women. The validity of this attribution depends, firstly, on the fact that the signal was independent of maternal respiratory movement or pulse rate and of fetal heart rate. When present the signal was within the range $30-90$ per minute, was prolonged for more than one fetal heart beat, and was of a rough character-that is, not a pure tone. It was also independent of fetal movements or hiccoughs perceptible to the mother. Alternate use of A-scan and continuous Doppler ultrasound systems in 32 patients showed that the audible signal had the same features as that of fetal breathing 